\title{
Periareolar Approach for Correction of Bilateral Asymmetric Tuberous Breasts
}

\author{
HESHAM A. HELAL, M.D. and EMAN Y. SADEK, M.D. \\ The Department of Plastic and Reconstructive Surgery, Faculty of Medicine, Ain Shams University, Cairo, Egypt
}

\begin{abstract}
Background: Patients with tuberous breasts suffer of psychosocial problems which may be aggravated with presence of asymmetry. Plastic surgeons should fully understand the developmental and anatomical basis of such deformity. The surgical plan is individualized according to the severity of deformity, presence of ptosis and degree of asymmetry. In this study we aim to correct the whole pathology and improve breast aesthetics in patients with bilateral asymmetric tuberous breasts.
\end{abstract}

Methods: 8 female patients with bilateral asymmetric tuberous breasts presented to outpatient clinic. Breast examination and measurements were done. Surgical correction with periareolar mastopexy and differential augmentation mammoplasty were done in all cases.

Results: Patients' mean age was (28.7) years. All patients had asymmetric breasts as regards; tuberous type, breast volume, projection, areola diameter, nipple and areolar complex position and degree of ptosis. Postoperatively, tuberous deformity was corrected in all cases. Good symmetry, and enhancement of breast volume and projection with naturallylooking breasts are achieved. Intermammary distance was tremendously decreased. Seven patients were highly satisfied, $(87.5 \%)$ one patient $(12.5 \%)$ as only satisfied.

Conclusion: Periareolar mastopexy approach, efficient release of constricting ring, repositioning of inframammary crease and differential breast augmentation are keys to achieve the best possible aesthetic outcome in managing tuberous breast asymmetry.

"Level of Evidence: Level IV".

Key Words: Bilateral tuberous Breast - Breast AsymmetryPeriareolar Mastopexy Approach - Repositioning of inframammary crease - Differential augmentation mammaplasty.

\section{INTRODUCTION}

The tuberous breast is a deformity caused by mal-development first described by Rees and Aston in 1976 [1]. Although it usually occurs in young females, however, it may occur in gynecomastia [2]. Plastic surgeons should fully understand the developmental and anatomical basis of the deformity. The superficial fascia is absent under the nippleareolar complex (NAC). There is a constricting ring of fibrous tissue at the periphery of NAC which is denser at lower pole of the breast, restricting the radial growth of breast parenchyma in one or all directions $[\mathbf{3 , 4 ]}$. Thus, the deformity is characterized by small mammary base, deficiency of horizontal and vertical dimensions, hypoplastic lower mammary quadrants, highly-situated inframammary crease (IMC), deficient inferior skin envelope and enlarged herniating NAC through the constricting ring $[\mathbf{1 , 3 , 5 - 8}]$. In addition to the common features of the deformity; Dinner and Dowden 1987 stated that the tuberous breast is usually ptotic [6]. Also, DeLuca et al., 2005 demonstrated the strong relation between breast asymmetry, constricted NAC and tuberous breast [9].

Many authors proposed different classifications of tuberous breast as regards severity [10-15]. Severity ranges from mild type with hypoplastic inferior medial quadrant of the breast to severe type with major hypoplasia of all four quadrants with various degrees of herniation of the breast parenchyma toward the areola.

There are multiple surgical techniques of correction of the tuberous breast which consider pathology and severity of each case. Tuberous breast surgery aims to release the herniated breast parenchyma through NAC, reposition high inframammary crease and provide adequate correction of both horizontal and vertical deficiency. Other considerations include; normal-size areola and correction of breast shape and volume. Surgeries could be designed as one- stage or multi-stage $[\mathbf{1 5}, \mathbf{1 6 , 1 7 ]}$. Some techniques used inframammary crease incision [18], some used periareolar incision [3,8,19-22] and some used both [5]. Augmentation of hypoplastic breast could be done by different 
methods; glandular flaps and breast reshaping $[\mathbf{8 , 2 3 , 2 4 ]}$; glandular flaps, shaping and implant technique $[\mathbf{3 , 2 0 , 2 2 , 2 5}$, glandular flaps, shaping, implant and mesh to provide repositioning of all components of breast $[\mathbf{1 9 , 2 1 ]}$ and tissue expander $[\mathbf{1 5 , 1 7 ]}$.

There are significant shortcomings associated with surgical correction of tuberous breast. Poor results may be caused by inadequate release of the constricting ring and failure to increase breast base and inferior pole volume [3,21]. Other complications include; widening of the areola, flattening of the breast, poor periareolar scars [26] and irregular bulges that can be seen through the skin envelope especially after using glandular flaps.

Patients with tuberous breasts suffer of psychosocial problems which may be aggravated in cases of bilateral asymmetric tuberous breasts. That is why special considerations for bilateral tuberous breast asymmetry are required as regards; diagnosis, breast anthropometry and surgical design to achieve the best possible aesthetic outcome.

\section{MATERIAL AND METHODS}

This is a prospective study included 8 female patients (16 breasts) with tuberous breast from June 2014 to March 2017. They complained of small asymmetric abnormal shaped breasts.

None of the authors has a financial interest in any of the products, devices or drugs mentioned in this manuscript. An informed consent for participation in the study was obtained from participants who also had signed an informed consent for approval of publication of photographs. This study was approved by The Ethical Committee of our University.

History taking, general examination and thorough local breast and axilla examinations were done. Breast dimensions in both breasts were measured including; areola diameter [AD], breast projection $[\mathrm{BP}]$, midclavicular-nipple distance $[\mathrm{M}-$ $\mathrm{N}]$, areola-inframammary crease distance $[\mathrm{A}-\mathrm{I}]$, breast width $[\mathrm{BW}]$ and inter-mammary distance [I-M] (distance between the most medial points of both breasts).

Ptosis degree (according to Regnault's classification [27], asymmetry, any chest deformity are noticed and recorded. We used Von Heimburg classification system to determine grade of breast deformity [13]. All patients had bilateral mammography for two reasons; first to detect any pathological lesion; and second to measure breast volume
[BV] using the formula proposed by Kalbhen et al., in 1999 [28].

Patient interviewing was done to recognize patient's needs and expectations from her perspective. The surgical plan was individualized according to the severity of deformity, presence of ptosis and degree of asymmetry. Both breasts were operated upon. Surgery aimed to correct the whole pathology present and to achieve aesthetic improvement of breast shape and volume. Table (1) shows the surgical steps needed to correct the tuberous pathology.

Table (1): Pathology of tuberous breast and surgical corrections.

\begin{tabular}{ll}
\hline Pathology & Correction \\
\hline $\begin{array}{c}\text { Adherent skin to the under- } \\
\text { lying pectoral fascia below } \\
\text { the level of NAC }\end{array}$ & $\begin{array}{c}\text { Sharp release to form lower } \\
\text { pocket }\end{array}$ \\
$\begin{array}{c}\text { Constricting ring denser at } \\
\text { lower part of the breast re- }\end{array}$ & $\begin{array}{c}\text { Crisscross scoring for effec- } \\
\text { tive release }\end{array}$ \\
$\begin{array}{c}\text { stricts the radial growth of } \\
\text { the breast parenchyma }\end{array}$ & \\
Herniating NAC & $\begin{array}{c}\text { Reposition of herniated } \\
\text { parenchyma }\end{array}$ \\
$\begin{array}{c}\text { Enlarged NAC } \\
\text { Deficiency of horizontal and } \\
\text { vertical development of } \\
\text { breast parenchyma (small } \\
\text { mammary base, hypoplastic } \\
\text { lower mammary quadrants, } \\
\text { shortened lower pole) }\end{array}$ & \\
implant & \\
Highly situated inframamma- & \\
ry crease & Repositioning to a lower \\
Ptosis & level \\
Asymmetry & Mastopexy \\
\hline
\end{tabular}

Surgical technique:

Preoperative Markings were done in the upright position. New NAC position and the circum-areolar pattern designed for mastopexy were marked. The breast base according to implant size and the preexisting Inframammary crease were outlined. The proposed new inframammary crease was marked at the level of the $5^{\text {th }}$ rib/intercostals space or $6^{\text {th }}$ rib according to each case.

Circum-areolar deepithelialization was performed reducing areola diameter to $4.2-5 \mathrm{~cm}$ according to the case. The gland was incised horizontally midway between lower border areola and skin of lower pole between 4 and 8 O'clock.

The gland was divided obliquely (caudal to cranial direction) down to pectoral fascia leaving an appropriate thickness of the gland attached to the lower skin flap (Fig. 1a). Dissection then 
started in a cephalic direction in the sub-glandular plane to create the upper pole pocket according to the predesigned space. The under surface of the gland was scored in a crisscross fashion using electrocautery till it is completely and properly stretched. Then the lower pocket was created by sharp dissection in the sub-glandular plane and continued inferiorly till the newly marked IMC. The undersurface of the lower gland was also scored in crisscross fashion as the upper gland. Skin at the old IMC level was sharply dissected in superficial radial manner to eradicate any residual memory.

The most caudal part of the stretched lower gland was then fixed to the inner aspect of the new IMC to pad the lower pole by three transcutaneous stitches. Those stitches were applied in a curvilinear fashion (i.e. medial and lateral sutures lie at the same level in relation to the rib cage while the middle one is located at the meridian at a lower level) to simulate the natural IMC. Each stitch was tied on small Vaseline gauze rolls (skinífasciaíglandískin). They were removed three weeks postoperative to allow adhesion and maintenance of the newly formed IMC (Fig. 1b).

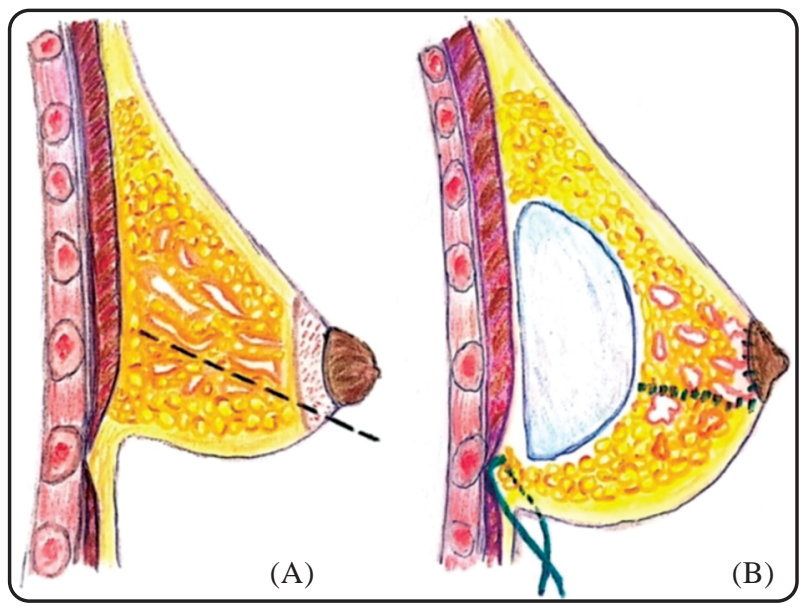

Fig. (1): (A) Circum-areolar deepithelialization to reduce areolar diameter and then breast gland is divided obliquely into main upper portion and small lower portion down to the pectoral fascia (dashed line). (B) The stitch is done through (skinífasciaíglandískin) and tied on a vaseline gauze, breast implant was then inserted in sub-glandular plane, the 2 portions of the gland is the sutured together to cover the implant and the areola is closed (dotted green lines).

Round, high profile, textured, cohesive gel implant was placed in the sub-glandular plane after meticulous hemostasis. Then gland was redraped and closed using absorbable monofilament 3-0 suture to completely cover the implant and produce a more natural shape.
Purse-string suture of the areola with nonabsorbable monofilament 3-0 suture was done to prevent its widening. Then closure of the circumareolar incision was completed with intradermal sutures using absorbable monofilament 3-0 suture. No suction drains were applied in all cases. Vaseline gauze was applied to NAC and adhesive tapes were applied along the lateral side and lower pole of the breast. Patients were advised to wear sports bra for one week postoperative.

Follow-up was done one week, two weeks, one month and 6 months postoperative. Patient's satisfaction was measured after 6 month as regards, shape, volume, symmetry and scars using (1 to 3) scale for each item. The whole score indicates patient's satisfaction; being (0-4): Not satisfied, (5-8): Satisfied and (9-12): Highly satisfied.

\section{RESULTS}

Patients' age ranged between 23 to 35 years with the mean age being (28.7) years. All patients gave history of affected breast development during puberty. All patients presented with bilateral asymmetric tuberous deformities. No patient had chest deformity. Preoperative measurements indicate that all patients had asymmetric breasts as regards, tuberous type, breast volume, projection, areola diameter, NAC position and degree of ptosis. Table (2) shows preoperative measurements of both breasts in each patient. Table (3) shows tuberous breast type according to Von Heimburg et al., 2000 classification [13], degree of ptosis and degree of asymmetry. Patients were followed-up for a mean duration of 18 months post-operative ( 6 to 24 months).

Tuberous deformity was corrected in all cases and naturally looking breasts with good symmetry was achieved. Postoperatively, all patients showed increased vertical and horizontal dimensions, areola-inframammary height, volume and projection. There was also decreased intermammary distance and improvement of breast asymmetry (Figs. 2,3). There were no complications in this study except for hypertrophic scarring in one case which was managed conservatively, widening of the scar in another case which was corrected with scar revision under local anesthesia and double-bubble deformity in the right breast of a third case. Seven patients were highly satisfied $(87.5 \%)$, while one patient $(12.5 \%)$ was only satisfied. 

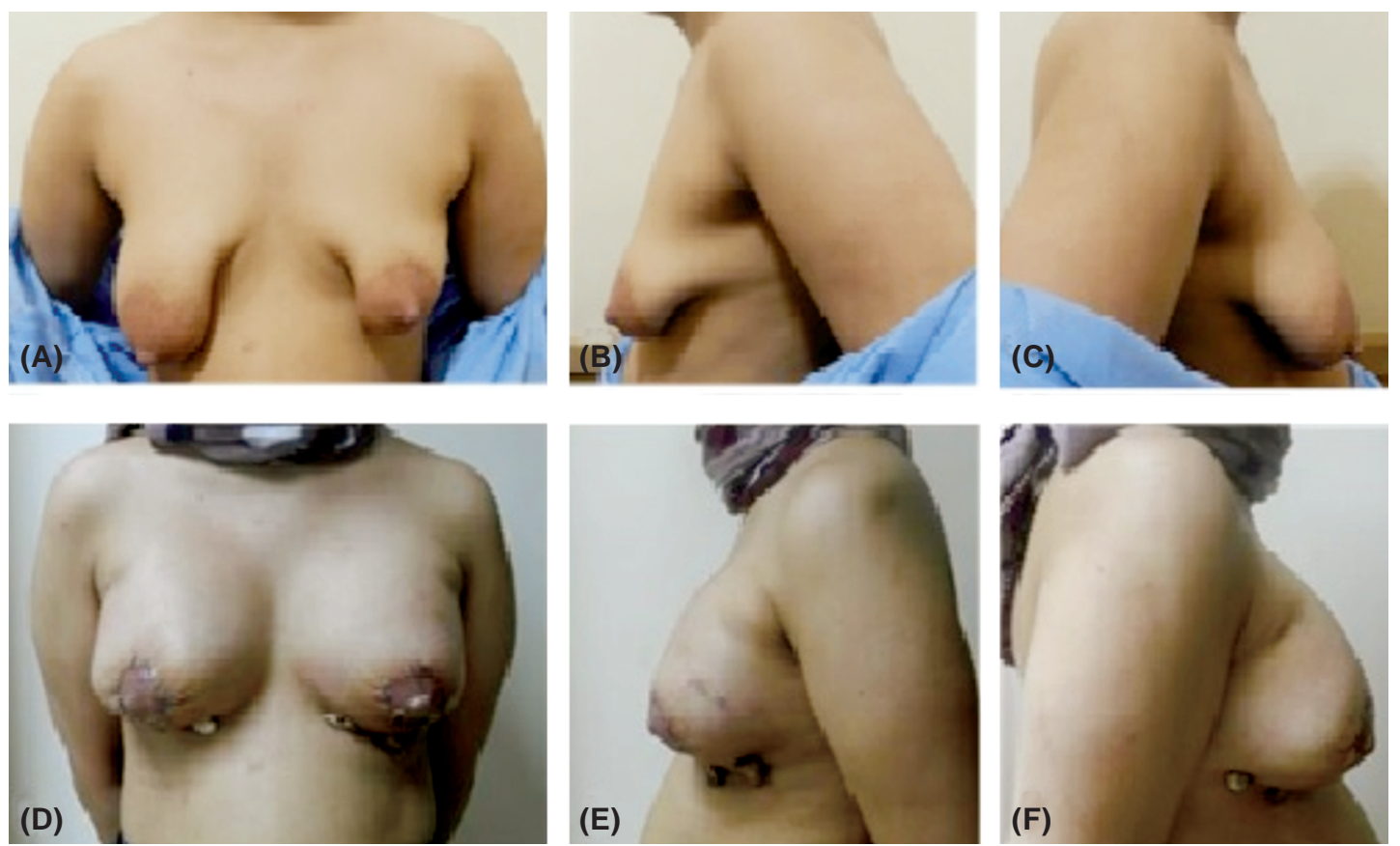

Fig. (2): 35y old female with bilateral asymmetric tuberous breast. (A,B,C) Show preoperative different views of type III tuberous right breast and type IV tuberous left breast with bilateral grade III ptosis, (D,E,F) Show 3 weeks postoperative different views with correction of all the tuberous breast and almost symmetrical breasts.
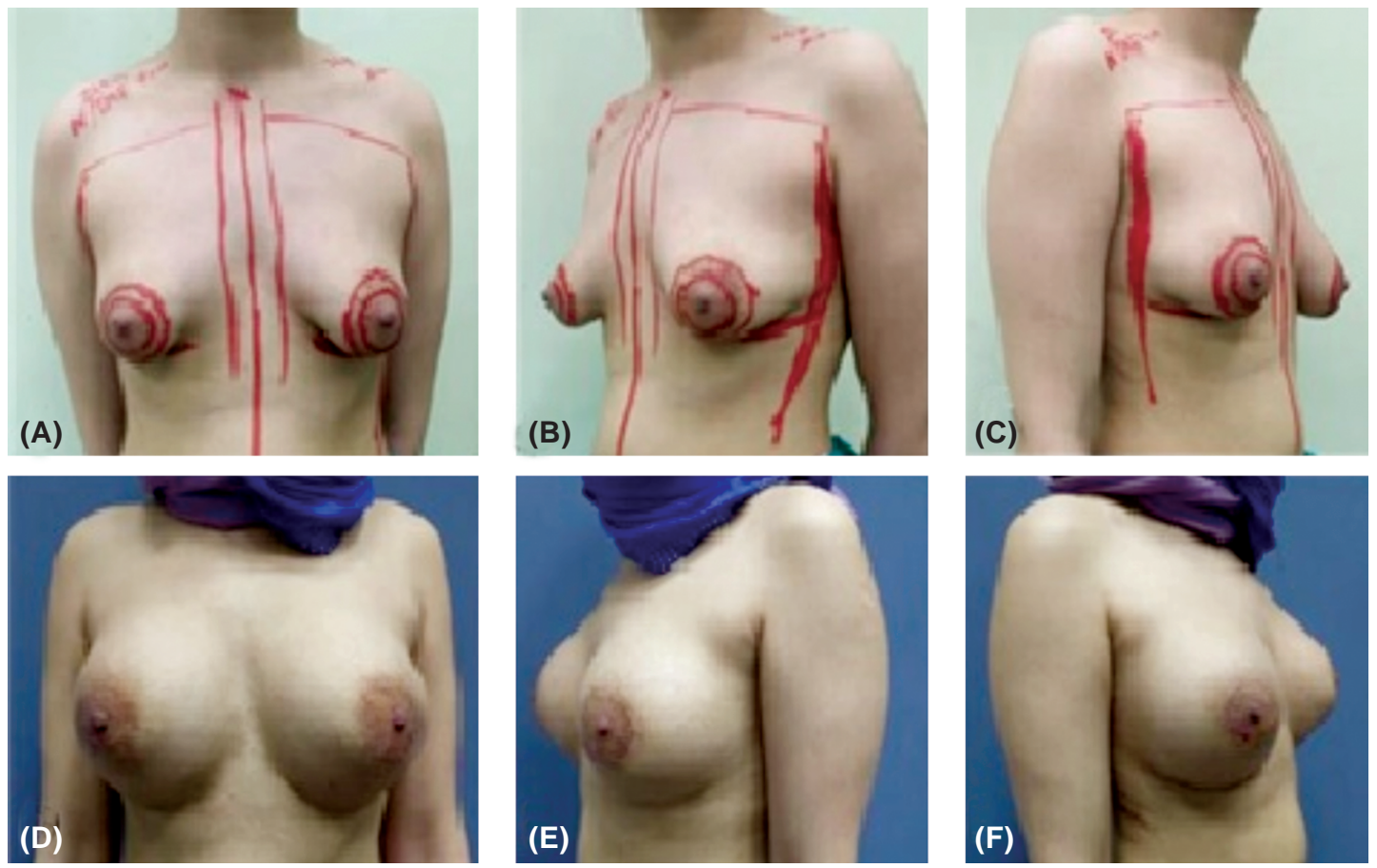

Fig. (3): 24y old female with bilateral asymmetric tuberous breast. (A,B,C) Show preoperative different views of type III tuberous right breast and type II tuberous left breast with bilateral grade I ptosis, (D,E,F) Show 4 months postoperative different views with correction of all the tuberous breast and almost symmetrical breasts. 
Table (2): Preoperative breast measurements.

\begin{tabular}{|c|c|c|c|c|c|c|c|c|c|c|c|c|c|}
\hline \multirow{2}{*}{ Pt. } & \multicolumn{2}{|c|}{ AD } & \multicolumn{2}{|c|}{ BP } & \multicolumn{2}{|c|}{ M-N } & \multicolumn{2}{|c|}{ A-I } & \multicolumn{2}{|c|}{ BW } & \multicolumn{2}{|c|}{ BV } & \multirow{2}{*}{ I-M } \\
\hline & Rt. & Lt. & Rt. & Lt. & Rt. & Lt. & Rt. & Lt. & Rt. & Lt. & Rt. & Lt. & \\
\hline 1 & 7 & 6 & 5 & 4 & 21 & 20 & 4.5 & 3.5 & 8 & 5 & 150 & 134 & 8.6 \\
\hline 2 & 9 & 7 & 4 & 3 & 26 & 24 & 3.8 & 3 & 9 & 6 & 170.5 & 108.8 & 12 \\
\hline 3 & 5 & 6 & 4 & 5 & 25 & 26 & 5 & 4.2 & 11 & 9 & 271.1 & 250 & 6.6 \\
\hline 4 & 6 & 5 & 5.5 & 4.5 & 24 & 21 & 5 & 4 & 10 & 9 & 220 & 140 & 10.1 \\
\hline 5 & 6 & 7 & 5 & 6 & 21 & 24 & 3.5 & 4 & 8 & 10 & 137.4 & 202 & 7.3 \\
\hline 6 & 5 & 4.5 & 3 & 2.8 & 21 & 20.5 & 5 & 4 & 9 & 8 & 115 & 100 & 7 \\
\hline 7 & 7 & 6 & 4 & 3 & 24.5 & 20 & 4 & 3.5 & 7 & 6.5 & 180 & 120 & 12.5 \\
\hline 8 & 6 & 8 & 4 & 5 & 22 & 23 & 3.5 & 4 & 6 & 10 & 115 & 138 & 11 \\
\hline
\end{tabular}

AD : Areola Diameter.

BP : Breast Projection.

BW: Breast Width.

M-A : Midclavicular-Nipple distance.

BV : Breast Volume.

A-I : Areola-Inframammary crease distance.

I-M: Inter-Mammary distance.

Table (3): Tuberous Breast Type according to Von Heimburg et al. 2000 classification, degree of ptosis and degree of asymmetry.

\begin{tabular}{|c|c|c|c|c|c|c|}
\hline \multirow{2}{*}{ Pt. } & \multirow{2}{*}{ Age } & \multicolumn{2}{|c|}{ Tuberous breast type } & \multicolumn{2}{|c|}{ Degree of ptosis } & \multirow{2}{*}{$\begin{array}{l}\text { Degree of asymmetry } \\
\text { According to tuberous deformity }\end{array}$} \\
\hline & & Right Breast & Left Breast & Right Breast & Left Breast & \\
\hline 1 & 23 & I & III & II & II & ++ \\
\hline 2 & 35 & III & IV & III & III & +++ \\
\hline 3 & 32 & I & II & III & III & + \\
\hline 4 & 28 & I & II & III & II & + \\
\hline 5 & 24 & III & II & I & I & ++ \\
\hline 6 & 27 & I & II & II & I & + \\
\hline 7 & 32 & II & III & III & III & ++ \\
\hline 8 & 28 & III & II & III & II & + \\
\hline
\end{tabular}

\section{DISCUSSION}

Tuberous breast deformity is considered a stigma for women. We agree with Dinner and Dowden 1987 [6] and DeLuca et al., 2005 [9] that the tuberous breast is usually ptotic and asymmetric. Preoperative breast measurements are crucial for successful operation. We add intermammary distance because it is apparently increased in tuberous deformity. We used mammography not only to exclude breast lesions, but also to measure breast volume.

Plastic surgeon should well understand the structural abnormalities. The absent superficial fascia below the areola $[29,30]$ and the constricting ring [10] which inhibits breast expansion and causes breast herniation into NAC.

Mandrekas and Zambacos [31] believed that the constricting ring represents a thickening of the superficial fascia. Histological study of this ring showed large concentrations of arranged longitudinal collagen and elastic fibers. The constricting ring exists at the periphery of NAC and it is denser at the lower part of the breast and does not allow the developing breast to expand. Also the deficient superficial layer of the superficial fascia below the areola caused the breast parenchyma herniation into NAC.

Thus, severity of tuberous deformity is related to severity of superficial fascia malformation. Also the constricted breast base is combined with the breast tissue deficiency [3], and any attempt to only augment the hypoplastic tuberous breast would accentuate the deformity. Any surgical technique that does not correct the whole existent anatomical deformity would have poor outcomes.

Asymmetry is common finding in tuberous breast deformity and it is very much related to discrepancies as regards; breast volume, shape, areola size, and degree of ptosis. We agree with Bach et al., [32] and Chen et al., [33] that breast symmetry especially breast shape is important and hard task to achieve. 
We used periareolar mastopexy approach. The gland was incised midway between lower border areola and skin of lower pole between 4 and 8 O'clock not along the inferior border of the areola which adopted by many other authors. We agree with Kolker and Collins [15] in that the periareolar approach provides better access for correction of tuberous breast deformities. While, using inframammary approach may not easily enable locating the IMC and correcting the areolar deformity. Also, the circumareolar scar could be forgiving unlike the inframammary scar especially if it is malpositioned [15].

In our study, we divided the gland obliquely down to the pectoral fascia into upper and lower glands. Thus, a relatively good portion of the lower gland was kept attached to the skin to be used in the coverage of the lower pole of the implant in the area between the old and newly proposed IMC. We think that keeping the lower gland attached to the overlying skin would not compromise vascularity. This is different of work of Galych et al., [34] and Innocenti and Innocenti [35], who separated the lower gland from the skin and use it to cover the implant.

We performed extensive crisscross scoring of the underneath of both gland portions similar to Galych et al., [34]. This type of scoring was done for two reasons; to effectively release the constricting ring and also to expand the sparse glandular tissues to cover the breast implant. Scoring was done by many authors with different techniques; performing radial incisions of mammary base [1], full-thickness incision through skin, subcutaneous tissue, and breast [6], horizontal transection of the constricting ring and using the inferior portion for auto-augmentation [8], vertical transection of constricting at $6 \mathrm{O}^{\prime}$ clock and created two pillars sutured in a "double-breasted" fashion in the inferior part of the breast $[\mathbf{3 , 3 2}]$ or dividing the gland to the pectoralis fascia and performing radial scorings [15].

In the present study we lowered the IMC in all cases to correct its highly-situated position, keeping it at $6 \mathrm{~cm}$ below the lower border areola. Thus the amount of sharp dissection and gaining of more height is related to the preoperative inframammary crease deficiency. Also we performed superficial radial sharp dissection of skin at the level of old IMC to eradicate any residual memory and we managed to avoid any double bubble deformity in all cases except one breast. Kolker and Collins left gland attached to the lower skin flap and performed radial scorings in the subcutaneous tissue. They assumed that this procedure would release constrictions and also alleviate the memory of the old inframammary crease [15].

We added three transcutaneous stitches to stretch the inferior glandular portion over the implant in between the old and new IMC (ranged from 1 to $3 \mathrm{~cm}$ ) where the inferior glandular envelope is usually deficient. Another importance of the stitches was to fix the new IMC in its natural curvilinear form not just a straight line. Galych et al., [34] also used few transcutaneous stitches to cover the implant with no details about the number or the fashion.

Discrepancy of volume in both breasts should be considered in augmentation. We performed differential augmentation mammaplasty to compensate for the hypoplastic breast according to the preoperative measurements. We do not use glandular flaps neither to augment nor to reshape the breast as this may end with visible irregularities. Reberio did not use implants as his patients were not concerned with large breast volumes [8]. Mandrekas et al., might add an implant to correct any volume deficiency [3]. Breast implant size was decided according to the desired volume. Different sizes were used in all cases. Persichetti et al., recommended use permanent expandable prosthesis for volume adjustment [36].

Correct placement of the implant with glandular re-draping could minimize unwanted outcomes such as recurrence of areola protrusion, doublecrease of the inframammary crease and "doublebubble" formation [10]. We inset the implant at the sub-glandular plane to get a normal shape and feeling. It could produce natural shape without being restricted by pectoralis major muscle. We re-draped the scored expanded upper and lower portions of the gland over the implant with good coverage. This helped shaping and avoiding rippling and double bubble deformity.

Many authors claimed that submuscular augmentation has many advantages, including; softer, more natural contour of the upper pole, increased soft tissue coverage, more durable breast position and decreased capsular contracture rates [37-41]. Bach et al., have inset the implant submuscular to provide better soft tissue coverage of the prostheses that could not be provided by the hypoplastic breast tissue and to reduce capsular contracture [32]. However they had reported a case with prosthesis dislocation. Kolker and Collins have put the implant at subpectoral dual plane as the lower pole requires the most "expansion" and implant-related shape definition more than the upper pole [15]. 
Non-absorbable circum-areolar purse string suture is a real secure to avoid postoperative areola widening. In our series, none of the patients complained of widening of the peri-areolar scar, regardless the amount of skin excised. Others had used GoreTex as Kolker and Collins [15].

Some authors corrected the deformity as multistage procedure [16,17]. However, Kolker and Collins put an algorithm for tuberous breast deformity [15]. They made the decision for two-stage with tissue expander when a fuller and bigger size is desired. On the contrary, we managed to correct all the deformity presented preoperatively as regards; tuberous shape, ptosis, asymmetry and abnormal inter-mammary distance along with high overall patients' satisfaction in one-staged procedure.

Although the sample of patients included in this study is relatively small and is considered the main limitation of the current study; we think that the described technique is readily applicable to all grades of tuberous breasts.

\section{Conclusion:}

Surgical plan for correction of bilateral tuberous breast asymmetry should be individualized according to the severity of deformity with special considerations regarding; diagnosis, breast anthropometry and surgical design. It is important to correct all contributing causes of the deformity to achieve the best possible aesthetic outcome.

\section{REFERENCES}

1- Rees T.D. and Aston S.: The tuberous breast. Clin. Plast. Surg., 3 (2): 339-347, 1976.

2- Klinger M., Caviggioli F., Villani F., Forcellini D. and Klinger F.: Gynecomastia and tuberous breast: Assessment and surgical approach. Aesthetic Plast. Surg., 33: 786787, 2009.

3- Mandrekas A.D., Zambacos G.J., Anastasopoulos A., Hapsas D., Lambrinaki N. and Iolannidou-Mouzaka L.: Aesthetic reconstruction of the tuberous breast deformity. Plast. Reconstr. Surg., 112 (4): 1099-1108, 2003.

4- Hanna M.K. and Nahai F.: Applied Anatomy of the Breast: The Art of Aesthetic Surgery: Principles and Techniques. St. Louis, Quality Medical Publishing, pp. 1790-1815, 2005.

5- Teimourian B. and Adham M.N.: Surgical correction of the tuberous breast. Ann. Plast. Surg., 10: 190, 1983.

6- Dinner M.I. and Dowden R.V.: The tubular/tuberous breast syndrome. Ann. Plast. Surg., 19 (5): 414-420, 1987.

7- Bohmert H. and Gabka C.J.: Plastic and reconstructive surgery of the breast. Thieme: Stuttgart, New York, pp 20, 1997.
8- Ribeiro L., Canz W., Buss A. and Accorsi A.: Tuberous breast: A new approach. Plast. Reconstr. Surg., 101 (1): 42-50, 1998.

9- DeLuca-Pytell D.M., Piazza R.C., Holding J.C., Snyder N., Hunsicker L.M. and Phillips L.G.: The Incidence of Tuberous Breast Deformity in Asymmetric and Symmetric Mammaplasty Patients, Plast. Reconstr. Surge., 1894-99, 2005.

10- Grolleau J.L., Lanfrey E., Lavigne B., Chavoin J.P. and Costagliola M.: Breast base anomalies: Treatment strategy for tuberous breasts, minor deformities, and asymmetry. Plast. Reconstr. Surg., 104: 2040, 1999.

11- von Heimburg D., Exner K., Kruft S. and Lemperle G.: The tuberous breast deformity: Classification and treatment. Br. J. Plast. Surg., 49: 339, 1996.

12- Meara J.G., Kolker A., Bartlett G., Theile R., Mutimer K. and Holmes A.D.: Tuberous breast deformity: Principles and practice. Ann. Plast. Surg., 45: 607, 2000.

13- von Heimburg D.: Refined version of the tuberous breast classification. Plast. Reconstr. Surg., 105: 2269, 2000.

14- Costagliola M., Atiyeh B. and Rampillon F.: Tuberous breast: revised classification and a new hypothesis for its development. Aesthetic Plast. Surg., 37: 896-903, 2013.

15- Kolker A.R. and Collins M.S.: Tuberous Breast Deformity: Classification and Treatment Strategy for Improving Consistency in Aesthetic Correction, Plastic and Reconstructive Surgery, 135: 73-86, 2015.

16- Toranto I.R.: Two stage correction of tuberous breast. Plast. Reconstr. Surg., 67 (5): 642-646, 1981.

17- Versaci A.D. and Rozelle A.A.: Treatment of tuberous breast utilizing tissue expansion. Aesthet. Plast. Surg., 15 (4): 307-312, 1991.

18- Williams J.E. and Hoffman S.: Mammaplasty for tubular breast. Aesthet. Plast. Surg., 5 (1): 51-56, 1981.

19- Sampaio Goes J.C.: Periareolar mammaplasty: Double skin technique with application of polyglactine or mixed mesh. Plast. Reconstr. Surg., 97 (5): 959-968, 1996.

20- Muti E.: Personal approach to surgical correction of the extremely hypoplastic tuberous breast. Aesth. Plast. Surg., 20 (5): 385-390, 1996.

21- Hodgkinson D.J.: Tuberous breast deformity: Principles and practice. Ann. Plast. Surg., 47 (1): 97-98, 2001.

22- Puckett C.L. and Concannon M.J.: Augmenting the narrow based breast: the unfurling technique to prevent the double bubble deformity. Aesth. Plast. Surg., 14 (1): 15-19, 1990.

23- Longacre T.J.: Correction of hypoplastic breast with special reconstruction of the "nipple type breast" with local dermoflap. Plast. Reconstr. Surg., 14 (6): 431-441, 1954.

24- Goulian D.: Dermal mastopexy. Plast. Reconstr. Surg., 47 (2): 105-110, 1971.

25- Biggs T.M., Taneja A. and Muti E.: The Art of Aesthetic Surgery: Principles and Techniques. St. Louis, Quality Medical Publishing, p. 2006, 2005.

26- Spear S.L., Giese S.Y. and Ducic I.: Concentric mastopexy revisited. Plast. Reconstr. Surg., 107 (5): 1294-1299, 2001. 
27- Regnault P.: Breast ptosis: Definition and treatment. Clin. Plast. Surg., 3: 193-203, 1976.

28- Kalbhen C.L., McGill J., Fendley P.M., Corrigan K.W. and Angelats J.: Mammographic determination of breast volume: Comparing different methods. Am. J. Roentgenol., 173: 1643-9, 23, 1999.

29- Hughes L.E., Mansel R.E. and Webster D.J.T.: Breast anatomy and physiology. In L.E. Hughes, R.E. Mansel, and D.J.T. Webster (Eds.), Benign Disorders and Diseases of the Breast: Concepts and Clinical Management. London: Bailliere Tindal, pp. 5-14, 1989.

30- Moore K.L.: The integumentary system. In KL Moore, The Developing Human: Clinically Oriented Embryology, $4^{\text {th }}$ Ed. Philadelphia: Saunders, pp. 426-428, 1988.

31- Mandrekas A.D. and Zambacos G.J.: Aesthetic reconstruction of the tuberous breast deformity: A 10-year experience. Aesthet. Surg. J. Sep., 30 (5): 680-92, 2010.

32- Bach A.D., Kneser U., Beier J.B., Breuel C., Horch R.E. and Leffler M.: Aesthetic Correction of Tuberous Breast Deformity Lessons Learned with a Single-Stage Procedure, The Breast Journal, 15 (3): 279-286, 2009.

33- Chan W.Y., Mathur B., Slade-Sharman D. and Ramakrishnan V.: Developmental Breast Asymmetry, The Breast Journal, 17 (4): 391-398, 2011.

34- Galych S.P., Dabizha O.Y., Kostenko A.A., Gomolyako I.V., Samko K.A. and Borovyk D.V.: Surgical Treatment of Tubular Breast Type II, PRS Global Open, 10; 4 (10): e1024, 2016.
35- Innocenti A. and Innocenti M.: Retro-Areola Distally Based Flap in the Management of the Full Expression of Tuberous Breast: A Simple Strategy to Resolve a Weak Point of the Deformity, Aesth. Plast. Surg., 39: 700-705, 2015.

36- Persichetti P., Cagli B., Tenna S., Simone P., Marangi G.F. and Vecchi G.L.: Decision Making in the Treatment of Tuberous and Tubular Breasts: Volume Adjustment as a Crucial Stage in the Surgical Strategy, Aesth. Plast. Surg., 29: 482-488, 2005.

37- Stevens W.G., Nahabedian M.Y., Calobrace M.B., et al.: Risk factor analysis for capsular contracture: A 5-year Sientra study analysis using round, smooth, and textured implants for breast augmentation. Plast. Reconstr. Surg., 132: 1115-1123, 2013.

38- Vazquez B., Given K.S. and Houston G.C.: Breast augmentation: A review of subglandular and submuscular implantation. Aesthetic Plast. Surg., 11: 101-105, 1987.

39- Henriksen T.F., Fryzek J.P., Hölmich L.R., et al.: Surgical intervention and capsular contracture after breast augmentation: A prospective study of risk factors. Ann. Plast. Surg., 54: 343-351, 2005.

40- Biggs T.M. and Yarish R.S.: Augmentation mammaplasty: A comparative analysis. Plast. Reconstr. Surg., 85: 368$372,1990$.

41- Blount A.L., Martin M.D., Lineberry K.D., et al.: Capsular contracture rate in a low-risk population after primary augmentation mammoplasty. Aesthet. Surg. J., 33: 516$521,2013$. 